\title{
Atitudes de leitura e efeitos de sentidos na escrita de dissertações do ProfLetras
}

\author{
Sulemi Fabiano Campos* \\ UFRN \\ Valnecy Oliveira Corrêa Santos ${ }^{* *}$ \\ UFRN \\ Recebido em: 30/o6/2019 \\ Aceito em: 20/12/2019
}

\begin{abstract}
Resumo: Neste texto, investigamos os efeitos de sentido(s) materializados na escrita de duas dissertações do Programa de Mestrado Profissional em Letras (ProfLetras), por meio do uso dos termos texto e gênero discursivo. Para tanto, ancoramo-nos nos fundamentos da Análise do Discurso, através dos quais mobilizamos conceitos como memória e interdiscurso. A análise dos dados aponta que os efeitos de sentido(s), construído(s) pelo uso dos termos texto e gênero discursivo, resultam em processos discursivos por metonímia e por sinonímia. Esses processos revelam como a força coercitiva do discurso Outro interfere na articulação entre o dizer do sujeito professor e o dizer teórico.
\end{abstract}

Palavras-chave: Leitura. Escrita acadêmica. Formação docente. Efeito de sentido(s).

Abstract: In this text, I investigate the effects of meaning(s) materialized in the writing of two thesis of the Professional Master's Program in Languages (ProfLetras), through the use of the terms text and discursive genre. This analysis is anchored in the foundations of Discourse Analysis, through which I mobilize concepts such as memory and interdiscourse. The data analysis points out that the effects of meaning(s), constructed(s) by the use of the terms text and discursive genre, result in discursive processes by metonymy and synonymy and reveal how the coercive force of the Another discourse interferes in the articulation between the subject teacher saying and the theoretical saying.

Keywords: Reading. Academic writing. Teacher training. Effect of meaning(s).

Resumen: En este texto, investigo los efectos de sentido (s) materializados en la escritura de dos disertaciones del Programa de Maestría Profesional en Letras (ProfLetras), por medio del uso de los términos texto y género discursivo. El análisis se basa en los fundamentos del Análisis del Discurso, a través de los cuales movilizo conceptos tales como memoria e interdiscurso. El análisis de los datos indica que los efectos de sentido (s), construidos (s) por el uso de los términos texto y género discursivo, resultan en procesos discursivos por metonimia y sinonimia y revelan cómo la fuerza coercitiva del discurso Otro interfiere en la articulación entre el decir del sujeto profesor y el decir teórico.

Palabras clave: Lectura. Escritura académica. Formación docente. Efecto de sentido (s). 


\section{Introdução}

Este texto é parte de um conjunto de escritos nos quais tematizamos a leitura e a escrita acadêmica, sendo esta compreendida como um acontecimento que materializa leituras, as lembradas e as esquecidas. Com base nessa compreensão, elegemos o termo “atitudes de leitura” com o intuito de representar a posição do sujeito que assume o centro da enunciação e diz eu, mobiliza saberes e constrói sentido(s) ao escrever um texto acadêmico. Para compreender as atitudes de leitura na escrita, analisamos a materialidade textual, a fim de identificar marcas linguísticas em torno das quais ocorre a produção de sentidos e de discursos. Buscamos, para tanto, estabelecer uma relação entre os níveis sintático, lexical, enunciativo e discursivo.

Neste texto, analisamos os efeitos de sentido(s) construídos na leitura e materializados na escrita, por um sujeito, professor da educação básica, ao escrever uma dissertação de mestrado profissional em Letras.

A definição desse objeto partiu de leituras realizadas sobre leitura e, mais especificamente, das leituras do corpus selecionado para a pesquisa que ora desenvolvemos - a leitura de dissertações produzidas no Programa de Mestrado Profissional em Letras (ProfLetras) -, na qual temos observado a leitura na escrita, através do(s) modo(s) como um sujeito, professor da educação básica e aluno de pósgraduação, ao vivenciar uma experiência de pesquisa, mobiliza a teoria para elaborar uma proposta de intervenção, para o ensino fundamental de 6o ao $9^{\mathbf{0}}$ ano e, assim, intervir na realidade escolar.

O corpus escolhido para esta análise é composto por duas dissertações do ProfLetras (doravante denominadas D1 e D2), defendidas em 2015, ano de conclusão das primeiras turmas formadas pelo programa, nas 42 universidades públicas conveniadas.

O presente texto está organizado em quatro seções. A primeira traz os fundamentos teóricos da Análise do Discurso, mais especificamente de Pêcheux (2009, 2015), que mobilizamos para realizar a análise linguístico-discursiva. Na segunda, apresentamos o corpus e o recorte metodológico. Na terceira seção, realizamos as análises. A última seção suscita um exercício de interpretação das atitudes de leitura depreendidas nas análises, no intuito de compreender o que essa ação nos diz acerca do processo formativo do professor e, de forma mais geral, da relação entre docência e conhecimentos no processo de (re)divisão do trabalho que estamos vivendo. 
Assim, este texto contém um exercício de leitura no qual a escrita acadêmica é compreendida como contexto de interlocução e como parte constitutiva do processo de formação.

\section{Os caminhos da leitura e o aporte teórico}

Os estudos desenvolvidos por Michel Pêcheux comportam, em sua historicidade, um percurso muito singular, entremeado pela busca permanente em construir um dispositivo de leitura para a análise do discurso. Assim, se no início de seu trabalho, por meio da Análise Automática do Discurso (AAD69), Pêcheux ([1990] 2014) propôs uma máquina discursiva de leitura com base em princípios de análise formal e na concepção de um sujeito totalmente assujeitado; em Discurso: estrutura ou acontecimento, ele propõe a leitura como ato de interpretação, no qual o analista deve observar os pontos de deriva, localizados nos espaços existentes entre a manipulação de significações estabilizadas e as transformações de sentido, sendo estas o foco de interesse do analista. Trata-se, segundo Pêcheux ([1988] 2015, p. 56), de "detectar os movimentos de interpretações enquanto atos que surgem como tomadas de posição, reconhecidas como tais, isto é, como efeitos de identificação assumidos e não negados".

Essa orientação de Pêcheux ([1988] 2015) implica compreender o sujeito como aquele que, embora ocupe o centro do encadeamento discursivo, transita entre dois territórios: o das significações estabilizadas, do consciente, do intradiscurso; e o do inconsciente, espaço das transformações do sentido, manifestas pelo interdiscurso. Implica, ainda, compreender que, imanente a todo ato de enunciar, encontra-se o ato de interpretar, ou seja, encontra-se o dizer como uma tomada de posição e efeito de identificação do sujeito. Por isso, a recomendação de Pêcheux ([1988] 2015) para, ao realizar uma análise, detectar os movimentos de interpretações, enquanto atos que surgem como tomadas de posição. Para ele, esses movimentos são possíveis de serem observados nas materialidades discursivas, no real da língua.

Ao utilizarmos termos como intradiscurso e interdiscurso, reportamo-nos a Pêcheux ([1988] 2009), segundo o qual o intradiscurso representa o imaginário vivido pelo sujeito de que ele é o responsável pelo dizer. É por meio desse mecanismo que o 
sujeito articula as partes constituintes do discurso, trazendo, para a superfície textual, na forma de um dizer, o interdiscurso.

O interdiscurso é, segundo Pêcheux ([1988] 2009), interior e anterior à existência do enunciado e seus efeitos interferem em sua estruturação. É o princípio de funcionamento da discursividade, pois representa o seu exterior, aquilo que, também na forma de dizer, interpela o sujeito e vem à tona, em um dado momento, no que ele diz. Trata-se de um processo que escapa ao plano da consciência, revelando a força coercitiva do discurso.

O interdiscurso coloca em evidência o real da história no real da língua, duas regiões bastante heterogêneas. O real da história está relacionado à constituição do sujeito como ser social. Antes de o sujeito existir como tal, já existe um real da história, com seu aparato de coisas a serem apreendidas e com seus discursos instituídos e/ou em processo de instituição, em meio ao qual, o sujeito é constituído.

$\mathrm{O}$ real da língua comporta o discurso enquanto materialidade, o que implica, segundo Gadet e Pêcheux (2004, p. 55), reconhecer a língua como objeto formal, mas que "não é costurado nas suas margens como uma língua lógica". O real da língua é marcado pela repetição, uma vez que a língua é estrutura e, como tal, possui suas normas que garantem uma certa estabilidade sintática; pelo novo, pois a forma de dizer e os sentidos construídos são tecidos nas relações enunciativas entre os sujeitos; e pelo equívoco, já que palavras e enunciados são sempre suscetíveis de se tornarem outros, diferentes de si mesmos (PÊCHEUX [1988] 2015). Essas três características fazem com que "um segmento possa ser ele mesmo e um outro, através da homofonia, da homossemia, da metáfora, dos deslizamentos, do lapso e do jogo de palavras, e do bom relacionamento entre os efeitos discursivos" (GADET; PÊCHEUX, 2004, p. 55). Quando se parte para a compreensão do dizer, é preciso sempre ter a percepção de que o real da língua comporta o sentido e que este é sempre resultado de uma construção social e histórica.

Pêcheux (2015a) alerta que toda sequência linguístico-discursiva possui como traço o interdiscurso, a heterogeneidade, por remeter a um já-dito, na forma de discurso outro (discurso relatado) e de discurso Outro (discurso do inconsciente), que irrompe na articulação da sequência. O discurso outro representa todas as vozes possíveis de serem identificadas na materialidade textual, sejam elas marcadas ou não. Já o discurso 
Outro representa, para Pêcheux ([1988] 2009), a Ideologia que constitui o sujeito, o inconsciente.

Pêcheux ([1988] 2009, p. 134), tendo como referência Althusser, afirma que "a Ideologia interpela os indivíduos em sujeito". O termo Ideologia, nesse enunciado, é colocado em maiúscula para indicar a Ideologia como o aspecto dominante da constituição do sujeito, sem o qual ele não existiria. Afirmar-se, por exemplo, como homem ou mulher, como forma de evidência, bem como afirmar-se segundo uma identidade social e jurídica é um efeito dessa constituição ideológica.

Já quando trata de ideologia, com inicial minúscula e com possibilidade de plural, Pêcheux ([1988] 2009) refere-se ao conjunto de conhecimentos, práticas e representações envoltos à constituição do ser humano, enquanto sujeito. As ideologias presentes nesse conjunto, denominado formações ideológicas, definem a maneira como o sujeito compreende o mundo e a sociedade que o rodeia. Ao tratar sobre formações ideológicas, Pêcheux ([1988] 2009) explica que o sujeito imerso numa formação ideológica não consegue separar-se dela. A realidade, por ele construída, é fruto de sua construção ideológica. O sujeito é, portanto, assujeitado, sua constituição social é resultado do conjunto de ideologias que o interpelam.

Detectar os movimentos possíveis de interpretações envolve, assim, a compreensão acerca da constituição do sujeito, pois, nesse âmbito, os sentidos são também construídos. No que se refere à construção de sentido(s), Pêcheux ([1988] 2009) defende o princípio da instabilidade, posto que, para o teórico, os sentidos são construídos na história, numa constante relação com o já-dito. Nessa concepção,

$$
\begin{aligned}
& \text { o sentido de uma palavra, de uma expressão, de uma proposição etc., não existe } \\
& \text { 'em si mesmo' (isto é, em sua relação transparente com a literalidade do } \\
& \text { significante), mas, ao contrário, é determinado pelas posições ideológicas que } \\
& \text { estão em jogo no processo sócio-histórico no qual as palavras, expressões e } \\
& \text { proposições são produzidas (isto é, reproduzidas) (PÊCHEUX, [1988] 2009, p. } \\
& \text { 146). }
\end{aligned}
$$

Quando utilizamos o termo efeitos de sentido(s), partimos desse princípio, considerando a formação discursiva como "lugar da constituição do sentido" (PÊCHEUX, [1988] 2009, p. 148) e compreendendo que os efeitos de sentido(s) podem ser depreendidos na relação entre os constituintes do enunciado que se dá na forma de articulação. 
O termo efeito(s) reporta, assim, a não existência do sentido literal, mas a transitoriedade, o equívoco e a falta que existem no real da língua. Palavras e expressões com sentidos diferentes podem, numa formação discursiva, ter o mesmo sentido, assim como palavras e expressões tidas como sinônimas podem ter sentidos diferentes. Esses movimentos de constituição do sentido ocorrem por meio do que Pêcheux ([1988] 2009, p. 148) denomina processo discursivo, "sistema de relações de substituição, paráfrases, sinonímias etc., que funcionam entre elementos linguísticos - 'significantes' - em uma formação discursiva dada”.

Pêcheux (2015a) nos adverte que a leitura em Análise do Discurso (AD) deve tomar como referência esse corpo de traços linguísticos e discursivos que formam uma memória, enquanto lugar de manifestação do interdiscurso. Ao utilizarmos o termo memória, temos como referência Pêcheux (2015b, p. 46), segundo o qual, memória é

aquilo que, face a um texto que surge como acontecimento a ler, vem restabelecer os 'implícitos' (quer dizer, mais tecnicamente, os pré-construídos, elementos citados e relatados, discursos-transversos etc.) de que sua leitura necessita: a condição do legível em relação ao próprio texto.

Quando consideramos o dizer como um ato de retorno sobre o já-dito, podemos compreender a memória também como disposição para o aparecimento do discurso, como parte integrante das condições de produção. Pêcheux ([1990] 2014), em AAD69, diz que são as condições de produção que determinam a irrupção do discurso, fazendo com que ele revele a forma do tecido sócio-histórico que o constitui. Pêcheux ([1990] 2014) define condições de produção como aquilo que evoca o que, fora do espaço da linguagem, permanece no já-dito e faz com que o discurso seja o que ele é. Nessa perspectiva, o sujeito enuncia a partir do lugar que se vê ocupante, bem como do lugar ocupado por seu interlocutor, a "antecipação do que o outro vai pensar parece constitutiva de qualquer discurso" (PÊCHEUX [1990] 2014, p. 77, grifo do autor). As condições de produção envolvem, assim, um jogo de imagens sociais, que Pêcheux ([1990] 2014) denomina de formações imaginárias.

Nesse jogo de imagens, aquilo que o sujeito diz é definido, ideologicamente, por um exterior, sendo a relação entre ele e o outro parte constitutiva desse dizer, o que envolve a imagem que o sujeito faz de si $\left(I_{A}(A)\right.$ - Quem sou eu para lhe falar assim?) e a imagem que o sujeito projeta de seu interlocutor $\left(I_{A}(B)\right.$ - Quem é ele para que eu lhe fale assim?) (PÊCHEUX [1990] 2014). Na primeira, o sujeito imagina-se numa dada posição 
que o habilita a dizer; na segunda, a posição ocupada por seu interlocutor interfere no dizer do sujeito. Na relação entre esses dois sujeitos, o discurso torna-se algo previsível e a realidade, por eles construída, é fruto de um imaginário.

Em Semântica e discurso, a concepção de condições de produção cede espaço para a de Formações Discursivas (FD), conceito advindo de Foucault ([1969] 2015) e incorporado por Pêcheux ([1988] 2009) à teoria de análise do discurso. O conceito de FD, de certa forma, engloba o de condições de produção. Quando Pêcheux ([1988] 2009, p.147) define FD - "chamaremos formação discursiva aquilo que, numa formação ideológica dada, isto é, a partir de uma posição dada numa conjuntura dada, determinada pelo estado de luta de classes, determina o que pode e deve ser dito" - ele realiza um retorno sobre o já-dito e, por meio do termo "isto é", encadeia o conceito de condições de produção ao de FD.

Por meio da noção de FD, a concepção acerca da constituição do discurso é modificada, passou-se a compreender que, numa mesma formação ideológica, há diferentes formações discursivas. Essa existência quebra a perspectiva de emergência do discurso como algo esperado, em função do lugar ocupado pelo sujeito e confere ao discurso o estatuto da heterogeneidade. Sendo o discurso heterogêneo, a formação discursiva passa a também possuir essa característica. A posição ocupada pelo sujeito passa a ser compreendida apenas como um referente, ponto sobre o qual se pode partir ao realizar uma análise. Como exemplo, diremos que, ao ler as dissertações do ProfLetras, temos como referente o sujeito professor da educação básica como aquele que ocupa a posição enunciativa e diz eu, o que não nos garante que esse sujeito se manterá nessa posição durante todo o trajeto da escrita, uma vez que ele é constituído em meio a dispersões, à heterogeneidade discursiva.

A concepção de FD provocou também modificações em relação à concepção de sujeito. A perspectiva de assujeitamento é mantida, todavia os efeitos causados pelo interdiscurso, por meio de seus elementos (o pré-construído e a articulação), e pelo discurso-transverso mostram o sujeito em processo, um sujeito que, pela ação do interdiscurso, mobiliza-se na FD. Os lugares por ele ocupados já não provêm apenas do exterior, das relações estabelecidas entre as lutas de classe, o sujeito age de uma certa forma sobre a articulação do dizer, pelo eixo do intradiscurso. 
O conceito de pré-construído foi formulado por Paul Henry ([1992] 2013) e incorporado por Pêcheux ([1988] 2009) como um dos elementos do interdiscurso. O préconstruído é uma espécie de mecanismo de sustentação linguística, por meio do qual o sujeito articula o dizer como espaço constituído por um presente e por uma memória. Trata-se de um fenômeno discursivo não identificado na superfície textual. Segundo Pêcheux ([1988] 2009, p. 151), “o 'pré-construído' corresponde ao 'sempre-já-aí' da interpelação ideológica que fornece-impõe a 'realidade' e seu 'sentido' sob a forma de universalidade ('o mundo das coisas')”. Trata-se da língua em funcionamento no sujeito, que produz o imaginário da realidade e da evidência do sentido.

O processo de articulação (também denominado sustentação) está relacionado à forma de organização e encadeamento dos enunciados, ao encaixe sintático. A “'articulação’ constitui o sujeito em sua relação com o sentido, de modo que ela representa, no interdiscurso, aquilo que determina a dominação da forma-sujeito" (PÊCHEUX, [1988] 2009, p. 151, grifo do autor). Pensar o processo de articulação em relação a evidência do sujeito e do sentido consiste em compreender esse processo como o responsável pela organização do dizer e, ao mesmo tempo, pelos indícios de que algo falha nessa organização.

Já o discurso-transverso pode ser compreendido como o atravessamento de um discurso em outro, como a presença de um conhecimento que se coloca ou que irrompe no dizer, marcando a existência de diferentes discursos no mesmo enunciado. Discursos, todavia, que quebram a sequência discursiva, embora conservem a linearidade do dizer. A relação entre o discurso-transverso e a articulação encontra-se no eixo do intradiscurso.

Pêcheux ([1988] 2009, p. 153) diz que “o funcionamento do 'discurso-transverso' remete àquilo que, classicamente, é designado por metonímia, enquanto relação da parte com o todo, da causa com o efeito, do sintoma com o que ele designa etc.” Em seguida, acrescenta que o discurso-transverso é uma forma do interdiscurso que "atravessa e põe em conexão entre si os elementos discursivos constituídos pelo interdiscurso enquanto pré-construído" (PÊCHEUX, [1988] 2009, p. 154).

A relação entre essas partes constitutivas do dizer, enquanto processo discursivo por metonímia, mostra que, ao mobilizar os conhecimentos, num plano intradiscursivo, o sujeito repete e/ou retoma discursos e é nessa relação que se dá o processo de Revista Investigações, Recife, v. 32, n. 2, p. 522 - 547, Dezembro/2019 
atravessamento, fazendo ecoar os diferentes discursos que o constituem. A presença de discurso-transverso mostra ainda a força coercitiva do discurso Outro e do discurso outro, uma vez que o sujeito, quando interpelado em sujeito-responsável (PÊCHEUX, [1988], 2009) tenta articular um dizer, mas é atravessado, discursivamente, por outro.

Uma análise do discurso implica, assim, o desenvolvimento de "gestos de leitura" (PÊCHEUX, 2010, p.51), no qual, os processos discursivos, presentes no real da língua, atrelados ao real da história, apresentam-se como caminhos para interpretar o que está posto na materialidade linguística, a fim de se chegar aos efeitos de sentido(s) construídos.

\section{Os caminhos da leitura: recorte metodológico}

Com base na concepção de leitura proposta por Pêcheux ([1988] 2015), a leitura do corpus parte do pressuposto de que a escrita acadêmica, por seu caráter científico, embora esteja inserida num universo discursivo logicamente estabilizado, é resultado de um processo de leitura e interpretação de textos científicos, ou seja, a escrita acadêmica expressa uma atitude de leitura. Assim, os caminhos da leitura, delineados para análise do corpus, visam a encontrar marcas linguístico-discursivas que possibilitem tematizar o processo de construção de sentidos e de discursos, a fim de buscar compreender atitudes de leitura na escrita de textos acadêmico-científicos.

Partindo desse pressuposto, realizamos a leitura do corpus e, nas idas e vindas pelas linhas dos textos, observamos que a maioria dos trabalhos coloca uma única e mesma perspectiva como centro do processo de ensino de Língua Portuguesa, o que nos fez compreendê-la como uma concepção que tem se tornado hegemônica no processo de ensino-aprendizagem de Língua Portuguesa.

Nesse movimento, percebemos a existência de outro processo: a assimilação de diferentes teorias a uma mesma proposta, ou seja, tem-se estabelecido uma relação de congruência entre estudiosos de linhas diferentes para sustentar a defesa de que um único objeto deve ocupar o centro do processo de ensino e aprendizagem de Língua Portuguesa. 
Como forma de exemplificar esses movimentos e por um recorte metodológico, para esta abordagem, escolhemos analisar passagens do corpus, nas quais há enunciados sobre texto e gêneros textuais/discursivos, ambos relacionados ao ensino-aprendizagem e tendo como enunciador o sujeito que escreve a dissertação, isto é, o professor da educação básica, mestrando do ProfLetras.

O termo passagem é utilizado, neste trabalho, como o lugar em que algo acontece; o ponto em que ocorre uma desestabilização de sentido, possível de ser abordada pela presença de processo discursivo. Já o termo enunciado é compreendido como o "nó de uma rede" (PÊCHEUX, 2015a, p. 143), ou seja, a sequência que constitui o espaço da memória. E, ao tomar como referentes, para a seleção das sequências, os termos texto e gêneros textuais/discursivos ${ }^{1}$, compreendemo-los como pistas para leitura do corpus, no sentido que Ginzburg (1989) dá a esse termo no paradigma indiciário.

\section{A leitura e análise do corpus}

Conforme já anunciado, partimos do método de leitura formulado por Pêcheux (2010, p. 51) que consiste em "mergulhar a 'leitura literal' (enquanto apreensão-dodocumento) numa 'leitura' interpretativa - que já é uma escritura”. Ao realizar esse tipo de leitura, buscamos compreender, na escrita de $\mathrm{D}_{1}$ e D2, as atitudes de leitura, que marcam, na escrita, os efeitos de sentidos.

A leitura integral do corpus permitiu-nos, como primeiro aspecto para o trabalho de leitura-escritura, atentar para a existência de uma unidade, nos dois textos: ao apresentar seus objetos de pesquisa, análise e intervenção, D1 e D2 declaram ter como objeto de ensino de língua portuguesa um gênero discursivo, conforme exposto no Quadro 1 que segue:

Quadro 1: Objeto ensino-aprendizagem apresentados por D1 e D2

\footnotetext{
${ }^{1}$ Utilizamos os termos textual e discursivo separados por barra, em função da recorrência dos dois termos no corpus analisado, ora está posto gênero discursivo, ora gênero textual. Temos ciência de que os termos não são permutáveis, pois advém de diferentes perspectivas teóricas. Optamos, todavia, por não fazer menção à especificidade dos termos no corpo do trabalho, para não fugir ao objetivo proposto. Optamos, ainda, por utilizar, a partir deste ponto, apenas o termo gênero discursivo.
}

Revista Investigações, Recife, v. 32, n. 2, p. 522 - 547, Dezembro/2019 


\begin{tabular}{|l|l|}
\hline D1 & $\begin{array}{l}\text { Selecionamos o gênero artigo de opinião como objeto de ensino-aprendizagem da } \\
\text { produção escrita na referida turma. A escolha se justifica pelo fato de que este } \\
\text { gênero propicia o aprimoramento das competências leitoras e produtoras de texto } \\
\text { (p.54). }\end{array}$ \\
\hline D2 & $\begin{array}{l}\text { Em termos pedagógicos, a carta do leitor figurou ao aluno como um objeto de } \\
\text { aprendizagem, atrelado às unidades básicas de ensino, no caso, as práticas de leitura } \\
\text { e análise linguística (p.115). }\end{array}$ \\
\hline
\end{tabular}

Fonte: Corpus da pesquisa

Para desenvolver o trabalho com o gênero artigo de opinião, Di organiza sua abordagem em torno de três eixos: o trabalho com leitura e produção textual; o trabalho com os gêneros textuais; abordagem sobre as características do artigo de opinião. D2, por sua vez, faz uma abordagem sobre a concepção sociointeracionista da linguagem e, nela, insere os gêneros discursivos e a carta do leitor, gênero que focaliza em sua proposta pedagógica, a partir da perspectiva da Linguística Aplicada.

Ao longo da exposição dos fundamentos teóricos e das atividades de intervenção e análise das produções dos alunos, D1 e D2 fazem declarações sobre o trabalho desenvolvido, nas quais ora se referem ao texto, ora ao gênero discursivo como objeto de ensino. Tendo lido integralmente os textos e feito seleção de alguns segmentos enunciativos, passaremos à análise, iniciando pelos segmentos coletados em D1. Seguem, assim, no Quadro 2, exemplos de segmentos enunciativos extraídos de D1.

\section{Quadro 2: Segmentos enunciativos extraídos de D1}

\begin{tabular}{|r|l|}
\hline 1 & As reflexões elaboradas por esses autores ${ }^{2}$ têm revelado que somente um processo de \\
2 & ensino-aprendizagem pautado na articulação entre o trabalho com a leitura e a escrita de \\
3 & gêneros textuais, que circulam socialmente, pode contribuir, decisivamente, para atingir- \\
4 & se o propósito de formar leitores e produtores de textos proficientes (p. 11). \\
5 & [...] defenderemos a concepção de leitura como um processo interacional, que envolve_o \\
6 & autor, o texto e o leitor (p. 14). \\
7 & Entendemos, então, que ao lermos um texto dialogamos com ele (p. 16). \\
8 & Entendemos, assim, que o alcance da familiaridade com a linguagem, por meio da leitura, \\
9 & amplia sobremaneira o repertório do produtor de textos [...] o trabalho de leitura dos \\
10 & gêneros na sala de aula contribui para a formação de uma postura mais reflexiva em \\
11 & relação ao uso da língua, pois ao analisar as formas composicionais dos textos, o aluno \\
12 & também reflete sobre a adequação dos elementos da linguagem aplicados à situação de \\
13 & produção e enunciação do gênero lido. (p. 21). \\
14 & Defendemos, então, que uma forma eficaz de minimizar a incidência de desvios \\
15 & gramaticais e de desvios de convenções da escrita, nas produções textuais dos alunos, \\
16 & \\
\hline
\end{tabular}

${ }^{2}$ D1 refere-se a Kleiman, Marcuschi, Koch, Rojo, Soares, Cagliari, Antunes, dentre outros. Citados no primeiro parágrafo da introdução.

Revista Investigaçũes, Recife, v. 32, n. 2, p. 522 - 547, Dezembro/2019 


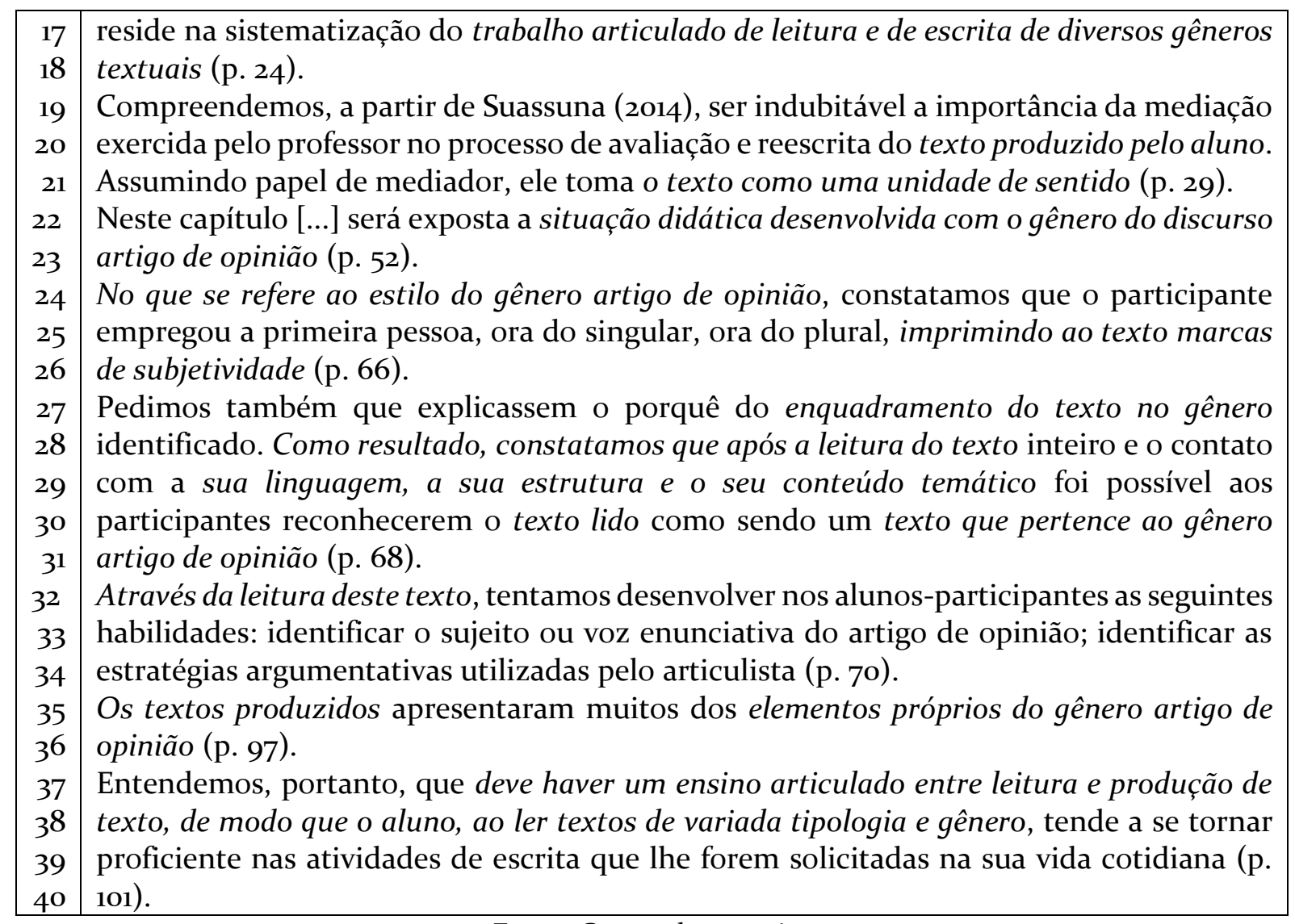

Fonte: Corpus de pesquisa

Nas linhas 1-4, que contém parte do primeiro parágrafo da introdução de D1, há uma justificativa para a escolha e definição do objeto de ensino-aprendizagem. Dı define seu objeto com base em argumentos de autoridade, utilizando-se do discurso outro na forma de intradiscurso: "As reflexões elaboradas por esses autores têm revelado que...” (L1). Em seguida, por meio de um efeito de distância do enunciado, produzido pelo discurso relatado, afirma: “...somente um processo de ensino-aprendizagem pautado na articulação entre o trabalho com a leitura e a escrita de gêneros textuais, que circulam socialmente, pode contribuir, decisivamente, para atingir-se o propósito de formar leitores e produtores de textos proficientes" (L1-4). Os advérbios "somente" e "decisivamente", bem como a oração subordinada adverbial final - "para atingir-se o propósito" -, seguida da substantiva completiva nominal - "de formar leitores e produtores de textos proficientes" -, ao mesmo tempo que sustentam, linguisticamente, por meio da interação entre os componentes sintático e lexical, o peso desse argumento, fazem eclodir, nesse processo de articulação do dizer, o discurso Outro.

A presença de um condicionante quanto à escolha do gênero discursivo artigo de opinião, por meio de oração subordinada adjetiva restritiva - "que circulam socialmente" 
- sinaliza a presença do discurso Outro. Há restrição em relação aos gêneros, os que circulam socialmente, estabelecendo, assim, uma divisão/separação no conjunto dos gêneros, apenas estes são objeto de ensino-aprendizagem.

Esse dado é marca de discurso-transverso e reporta a discursos como os da teoria da comunicação que trouxe para o contexto do ensino-aprendizagem os textos pragmáticos sob o álibi de serem esses os mais acessíveis. Discurso que se consolidou nos Parâmetros Curriculares Nacionais de Língua Portuguesa (PCNLP). São acontecimentos que antecedem a escrita de D1, mas que, de certa forma, são atualizados por meio dela, podendo ser indício também de um condicionante ideológico para a “escolha” de D1 pelo gênero artigo de opinião. Nesse trecho, embora o discurso relatado atribua o dizer a um conjunto de estudiosos citados por D1, é possível ainda observar a sequência como efeito de identificação que reporta o discurso a uma memória discursiva, a um já-dito, presença imanente do outro na sequência.

Apesar da afirmação de que o gênero artigo de opinião é o objeto de ensinoaprendizagem e do argumento de autoridade expresso pelo acionamento das vozes dos estudiosos citados, o gênero, objeto declarado por D1, é mencionado como objeto em apenas três ocorrências relacionadas ao ensino, à sala de aula: "leitura do gênero" (L910); "trabalho articulado de leitura e escrita de gêneros textuais" (L16-17); "a situação didática é desenvolvida com o gênero do discurso artigo de opinião” (L22-23). Em contrapartida, Dı marca, na escrita, a presença do texto como objeto, ao afirmar que o processo interacional envolve o texto ( $\left.\mathrm{L}_{5-7}\right)$; dialoga-se com o texto (L7); lê-se textos (L7, L28, L30, L32, L37-38); produz-se textos (L9, L15, L19-20, L35, L37-38); analisa-se as formas composicionais do texto (L11); o texto como a unidade de sentido (L20-21); ensina-se por meio de textos (L37-38).

A leitura de Di permitiu-nos observar, entre esses dois polos, pontos em que os termos gênero discursivo e texto são apresentados no mesmo segmento, ora como permutáveis, ora interligados. Nas linhas 24-26, Di escreve: "No que se refere ao estilo do gênero artigo de opinião, constatamos que o participante empregou a primeira pessoa, [...] imprimindo ao texto marcas de subjetividade". O enunciado focaliza o estilo do gênero artigo de opinião, porém as marcas de subjetividade são impressas no texto. Nas linhas 28-29, está posto: "Como resultado, constatamos que após a leitura do texto inteiro e o contato com a sua linguagem, a sua estrutura e o seu conteúdo temático”. O 
texto é objeto de leitura, mas o enunciado "contato com a sua linguagem, a sua estrutura e o seu conteúdo temático" reporta ao dizer bakhtiniano de que o gênero possui, estrutura, conteúdo temático e estilo. O mesmo ocorre nas linhas 9-10, "o trabalho de leitura dos gêneros na sala de aula”, mas as formas composicionais são dos textos (L11) e a situação de produção e enunciação é do gênero lido (L13).

Nesses enunciados, é possível observar a presença do processo discursivo por sinonímia, uma vez que os termos texto e gênero do discurso são utilizados como permutáveis, numa relação de equivalência de sentido. Essa afirmação fundamenta-se, ainda, em Dubois et. al. (2006, p. 555), segundo o qual "dois termos são ditos sinônimos quando têm a possibilidade de se substituírem um ao outro num único enunciado isolado". É fato que, ao situar os termos texto e gênero discursivo em suas respectivas bases teóricas, eles não possuem o mesmo significado, todavia, em D1, é possível ler os enunciados em análise fazendo a substituição entre os termos.

O que Di desenvolveu foi um trabalho com o texto, embora tenha buscado trazer para o centro do processo textos que pertencem ao gênero artigo de opinião. O termo "formas composicionais dos textos", apesar de não vir marcado como discurso outro, traz à memória o enunciado bakhtiniano, que se refere às formas composicionais do gênero. O que se produz e se enuncia, ações evocadas na linha 13, são textos, constituídos na forma de determinados gêneros. Nesses segmentos, os termos gênero discursivo e texto representam, assim, o mesmo referente.

A constituição desse processo discursivo ocorre em função do interdiscurso que, na forma de discurso-transverso, atravessa os enunciados pela força de dois discursos em embate, numa mesma formação discursiva: o que defende o texto como objeto e o que defende o gênero discursivo. Nesse embate, aparece o conflito entre o que se disse antes sobre o gênero ou sobre o texto e o que Di diz sobre eles.

Na página 54, há outra ocorrência similar, quando D1 escreve "melhorar, com a aplicação de um trabalho de leitura e produção do gênero do discurso artigo de opinião, a qualidade da posição de leitor e de produtor de texto dos alunos-participantes”. D1 declara que um trabalho de leitura e produção do gênero do discurso artigo de opinião implica na qualidade da posição de leitor e de produtor de texto. Embora essa declaração tenha um viés de coerência, o que o aluno ler e produz é o texto, não o gênero. Já na página 56, acrescenta: "na apresentação da situação, o professor expõe aos alunosRevista Investigações, Recife, v. 32, n. 2, p. 522 - 547, Dezembro/2019 
participantes um projeto de trabalho que começa com a produção do gênero escolhido e vai ser concluído com a produção final desse texto”. Nesse caso, Di utiliza um termo anafórico esse (de + esse) como dêitico da expressão "a produção do gênero [texto] escolhido".

Também nesses segmentos, os termos gênero discursivo e texto representam o mesmo referente. São associados por meio de uma relação de sinonímia. Esse efeito de sentido marca-se por meio dos movimentos feitos na escrita, nos quais se depreende um efeito de identificação, produzido por meio do léxico, do uso e adesão de termos próprios de uma corrente teórica. Di, ao afirmar ter como objeto de ensino-aprendizagem o gênero artigo de opinião, denota esse efeito no fio do discurso, no intradiscurso. Os segmentos de afirmação/julgamento - "o trabalho de leitura dos gêneros na sala de aula contribui para a formação de uma postura mais reflexiva em relação ao uso da língua” (p. 22); "melhorar [...] com a aplicação de um trabalho de leitura e produção do gênero do discurso artigo de opinião, a qualidade da posição de leitor e de produtor de texto dos alunos-participantes" (p. 54) - presentes nos momentos em que D1 assume o ato enunciativo e declara utilizar como objeto o gênero do discurso sustentam esse efeito. Nesse ponto, é possível observar a presença do efeito-sujeito, como forma de identificação imaginária com o discurso que sustenta a defesa de que o gênero é o objeto de ensino-aprendizagem, embora o que se marque com maior intensidade, na escrita de D1, seja o discurso que defende o texto como unidade de ensino.

Frente ao exposto, considerando que os segmentos postos em relação atravessam todo o texto em análise, concluímos que a força coercitiva do discurso, presente na formação discursiva observada na escrita de D1, faz eclodir uma inconsistência no texto: o gênero artigo de opinião é o objeto declarado por D1; o texto é, todavia, o objeto mobilizado, marcado, com maior recorrência, na escrita.

Seguindo o percurso de leitura, passamos agora para análise de D2, trabalho cuja proposta focaliza o ensino de língua portuguesa por meio do gênero discursivo carta de leitor. Seu referencial é organizado com base em duas temáticas centrais: a abordagem sociointeracionista da linguagem; aplicações e o ensino de língua portuguesa através dos gêneros textuais, com foco nos fundamentos da Linguística Aplicada.

Como forma de guiar a leitura, analisamos, primeiramente, quais os processos discursivos estão presentes em D2, a fim de observar como os efeitos de sentido marcam- 
se por meio dos movimentos feitos na escrita. Para tanto, partimos da leitura integral do texto, através da qual, buscamos recuperar os movimentos mais recorrentes no corpus, quando os termos texto e gênero discursivo são mobilizados na escrita. O Quadro 3 contém exemplos de segmentos em que as ocorrências aparecem de forma mais marcada, na escrita.

Quadro 3: Segmentos enunciativos extraídos de D2

\begin{tabular}{|c|c|}
\hline 1 & \\
\hline 2 & 20 \\
\hline 3 & fundamental, com o gênero discursivo a carta do leitor (p. 12). \\
\hline 4 & Em consonância com esses autores [Geraldi $(1997,2006)$, \\
\hline 5 & pesquisa de mestrado que a prática de análise \\
\hline 6 & linguística deve ser definida como um processo de reflexão da língua em uso pelos alunos \\
\hline 7 & que analisarão textos (p. 14). \\
\hline 8 & lo a linguagem como espaço de interação entre os sujeitos, \\
\hline 9 & de um trabalho pedagógico com os gêneros d \\
\hline 10 & acidade discursiva do nosso aluno [...] Ressaltamos qu \\
\hline 11 & opção pelo gênero jornalístico, no caso, a carta do leitor, deve-se à contempor \\
\hline 12 & dos cc \\
\hline 13 & lítico at \\
\hline 14 & por $n$ \\
\hline 15 & sujeitos com capacidade de atuação entre si, na medida em que compartilham de seus \\
\hline 16 & saberes e dos encontrados nesses textos, organizados em determinados gêneros \\
\hline 17 & discursivos (p. 26). \\
\hline 18 & que considerar o texto sob a perspectiva enunciativa da lingua \\
\hline 19 & ém de \\
\hline 20 & o integrado, favorece também \\
\hline 21 & o processo de desenvolvimento da leitura crítica, na medida em que, a partir da interação \\
\hline 22 & produção da contrapalavra para os \\
\hline 23 & interl \\
\hline 24 & e o texto traz (p. 30). \\
\hline 25 & [...] A interlocução deve ser o ponto de partida para o trabalho com o texto (p. 35). \\
\hline 26 & O estudo dos gêneros discursivos tem grande relevância para o \\
\hline 27 & $a$, em especial, para a prática de leitura (p. 38). \\
\hline 28 & Destacamos que esses mecanismos gramaticais, discursivos, empregados na \\
\hline 29 & er priorizados pelo professor nas práticas de leitura e \\
\hline 30 & uística para observação dos efeitos de sentido produzidos pela língua em uso \\
\hline 31 & (p. 45). \\
\hline 32 & Daí, a importância de que a escola oportunize aos alunos a apreensão dos mais diversos \\
\hline 33 & $\operatorname{vos} \mathrm{pc}$ \\
\hline 34 & [...] trabalhar os gêneros que de fato possam aprimorar o seu domínio discursivo e lhe \\
\hline 35 & izem uma pal \\
\hline 36 & ciais, materializadas em gêneros discursivos (p. 48). \\
\hline 37 & Consideramos fundamental no processo de ensino e aprendizagem adentrar no processo \\
\hline 38 & o da carta do leitor (p. 54). \\
\hline
\end{tabular}




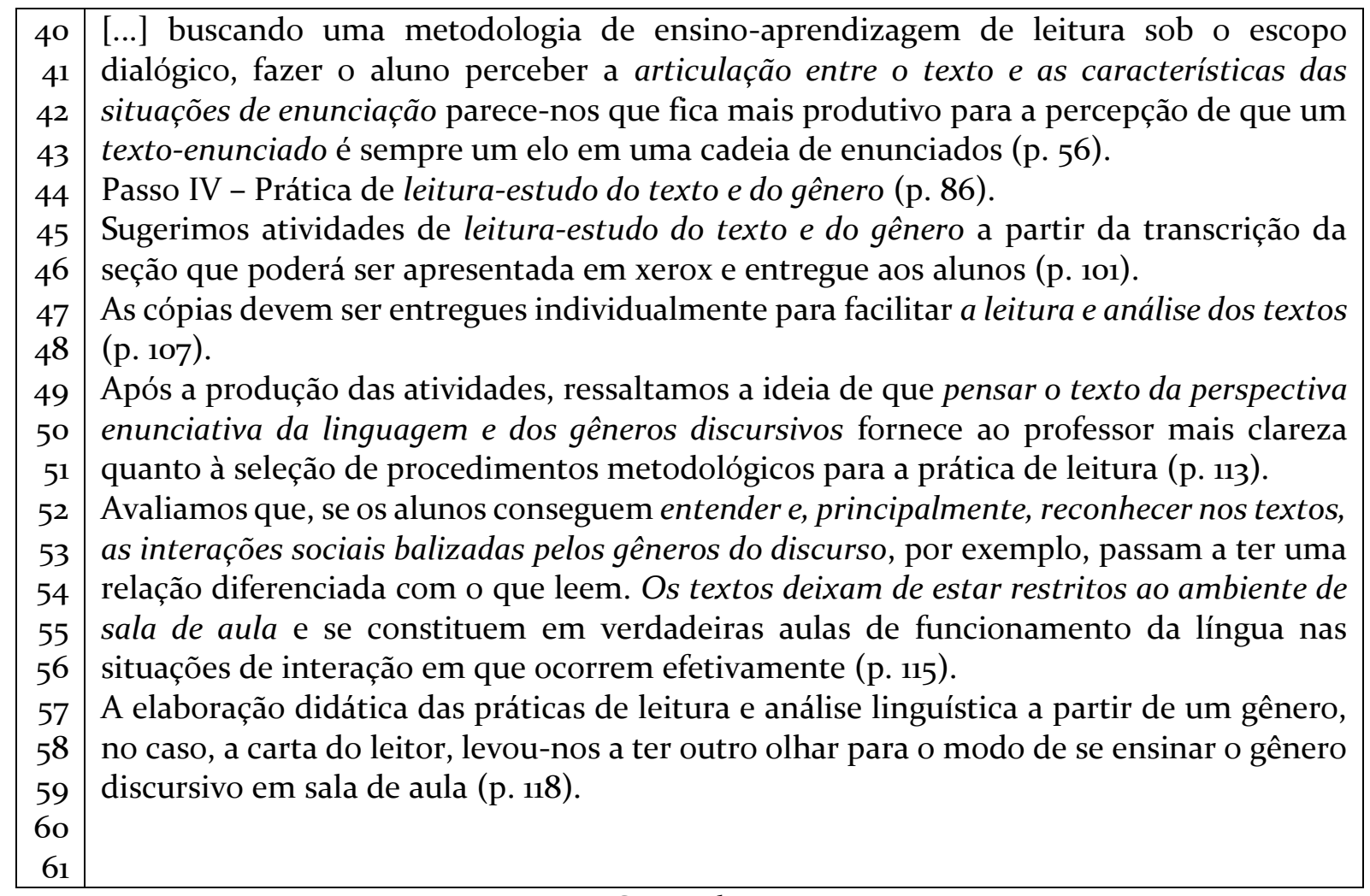

Fonte: Corpus de pesquisa

Em D2, nas linhas 1-3, há a declaração sobre a escolha do objeto - gênero carta de leitor - para o trabalho de elaboração de proposta pedagógica de leitura e análise linguística. Assim como D1, D2 parte de argumentos de autoridade, inseridos, no texto, por meio do discurso relatado, "Em consonância com esses autores" (L4). Esse segmento retoma seis parágrafos da introdução, nos quais, D2 apresenta as concepções teóricas dos autores citados. $\mathrm{O}$ argumento utilizado, todavia, não reporta para a escolha do objeto gênero carta de leitor, mas ao texto: "também defendemos em nossa pesquisa de mestrado que a prática de análise linguística deve ser definida como um processo de reflexão da língua em uso pelos alunos que analisarão textos” (L5-7). Nesse enunciado, D2 identifica-se por meio da primeira pessoa, atribuindo a si a responsabilidade enunciativa e defende o uso do texto como unidade de ensino. Em seguida, na mesma página e utilizando do mesmo recurso linguístico - uso da primeira pessoa - D2 afirma: “julgamos que a realização de um trabalho pedagógico com os gêneros discursivos é relevante para o desenvolvimento da capacidade discursiva do nosso aluno" (L8-10). Marca, assim, a adesão ao gênero discursivo como objeto de ensino-aprendizagem.

A essas declarações, D2 acrescenta que a interação decorre por meio do texto (L14 e L22); os textos são organizados em determinados gêneros discursivos (L16-17); o texto 
traz saberes (L25); o trabalho com o texto (L26); faz-se leitura e análise do texto (L4748); pensa-se o texto na perspectiva enunciativa (L49-50); os textos deixam de estar restritos ao ambiente de sala de aula (L55-56). Há, assim, movimentos de transitoriedade entre os termos texto e gênero discursivo bem marcados, na escrita de D2.

Nesse ir e vir pelos movimentos do texto, enquanto espaço discursivo, o uso da primeira pessoa cria o efeito-sujeito, por meio de um imaginário de que o sujeito, ao dizer eu, é a fonte do sentido. O processo de assujeitamento discursivo, todavia, irrompe, no texto, por meio do real da língua, enquanto espaço de memória, quando D2 acrescenta: "Ressaltamos que a nossa opção pelo gênero jornalístico, no caso, a carta do leitor, deve-se à contemporaneidade desta quanto à abordagem dos conteúdos, uma vez que trata de um momento social, histórico e político atual (L10-13). Dizer que reporta ao mesmo condicionante presente na escolha de D1: a escolha por gêneros que circulam socialmente, gêneros da atualidade.

Esses segmentos postos por D2 denotam a força do interdiscurso, na forma de discurso-transverso, pois traz à tona, numa mesma formação discursiva, diferentes discursos, o que defende o texto como objeto; o que defende o gênero como objeto e outro, bem anterior a esses, que defende a presença dos textos pragmáticos no processo de ensino-aprendizagem de Língua Portuguesa. É por meio dessas relações que a língua, como afirma Pêcheux (2010, p. 57), “encobre um jogo”, do qual eclodem, na interação entre os níveis sintático e semântico, os processos discursivos que marcam, linguisticamente, os efeitos de sentido.

Os segmentos coletados em D2 mostram que o termo gênero discursivo é destacado sempre que a referência é ao ensino: L2-3, L9, L27, L33-34, L44, L45, L59-61. Nesses casos, a forma como o termo gênero discursivo é introduzido sinaliza o efeito de identificação de D2 com o discurso que defende o gênero como objeto de ensino de língua portuguesa. Nas L2-3 e L9, os gêneros são apontados como instrumento de trabalho pedagógico; nas L16-17 e L35-37, D2 justifica sua escolha, ao afirmar que os textos são organizados em gêneros; uma das características do texto é ser organizado em gêneros; as práticas sociais materializam-se em gêneros. Assim, para o aluno aprender sobre os textos, precisa estudar os gêneros. Nas L27, L44, L45, D2 reitera o meio e, ao mesmo tempo, o instrumento de sua ação, ou seja, o que se propõe é a leitura, estudo e produção do gênero carta de leitor.

Revista Investigąções, Recife, v. 32, n. 2, p. 522 - 547, Dezembro/2019 
D2 sustenta, pelo discurso, a defesa desse objeto: a interação decorre por meio de textos (L14), mas é balizada pelos gêneros do discurso (L54). Nas L59-61, culmina a opção pelo objeto, "A elaboração didática das práticas de leitura e análise linguística a partir de um gênero", ou seja, as práticas serão embasadas no gênero. Nas L6o-61, o argumento se desvela e o objeto se define pelo enunciado "ensinar o gênero discursivo em sala de aula". O efeito de identificação mantém-se ao longo de todo o texto de $\mathrm{D}_{2}$, quanto a opção pelo gênero do discurso como objeto de ensino.

Há, todavia, diversos segmentos em que o texto é colocado em destaque: L7, os alunos analisarão textos; L14 e L22, a interação decorre/é promovida por meio de textos; L25-26, o texto traz saberes; L41-42, o texto se articula às situações de comunicação; L4748, os alunos leem e analisam textos; L55-56, os textos não ficam restritos ao ambiente de sala de aula e se constituem em verdadeiras aulas de funcionamento da língua nas situações de interação em que ocorrem efetivamente. Nesses casos, a referência é ao texto como unidade de ensino e como prática social. O gênero como prática social é mencionado em duas ocorrências, L36-37 e L53-54. Considerando a articulação entre os enunciados, no engendramento do texto, podemos sustentar a existência de dois discursos em embate, numa mesma formação discursiva: o que defende o texto como objeto de ensino e o que defende o gênero discursivo como objeto de ensino. Nessa relação de transitoriedade entre os dois objetos, ao tomar como referência o efeito do interdiscurso, na forma do discurso-transverso, é possível compreender os termos texto e gênero como permutáveis nesses enunciados, o que conduz a um processo discursivo por sinonímia.

Há, todavia, cinco ocorrências que levam a outro processo discursivo. Nas linhas 16-17, D2 afirma que os textos são organizados em determinados gêneros. Nesse caso, os termos texto e gênero são aproximados por uma relação parte e todo. Os textos representam o todo e os gêneros a parte. Assim, uma das características do texto é ser organizado em gênero. Nas L18-19 e L49-50, D2 afirma que o texto deve ser considerado sob a perspectiva enunciativa da linguagem e dos gêneros discursivos. A relação parte e todo permanece, todavia com a ordem invertida, o texto é a parte e o gênero é o todo. $\mathrm{O}$ texto está subordinado às duas perspectivas, a enunciativa e a do gênero. Já nas linhas L44 e L45, texto e gênero são ligados pela conjunção "e”, uma forma de encaixe que marca efeitos de sentidos de relação entre os dois termos, apresentando-os como duas 
categorias distintas, mas interligadas, uma vez que o segundo elemento é acrescido ao primeiro numa relação de causa e consequência: leitura-estudo do texto e do gênero. $O$ texto representa o todo e a leitura-estudo do todo, favorece a leitura-estudo da parte, o gênero.

Nesses casos, temos um processo discursivo por metonímia, cujos efeitos de sentido marcam a presença do discurso-transverso, um discurso atravessa um outro discurso, sem, com isso, suprimi-lo. A relação entre esses dois discursos marca a presença de um sujeito dividido que, ao retomar um já-dito, retoma também um outro, fazendo coexistir, em um mesmo enunciado, duas realidades distintas. Isso em função das diferentes ideologias que o interpelam. Essas duas realidades não se alinham, embora, na linearidade linguística, isso não se torne perceptível. O enunciado, pelo efeito metonímico, passa a ter duas partes de um todo que não se fecha, deixando transparecer o discurso-transverso.

A presença desses movimentos - processo discursivo por sinonímia e por metonímia -, marcados, na escrita, por meio da língua, indica a busca em articular o dizer de D2 ao dizer teórico, ou seja, a busca por dizer o que está presente no discurso que defende o gênero como objeto, por marcar um efeito de identificação. A força coercitiva do discurso manifesta por meio do interdiscurso, provoca a irrupção de outro dizer, fazendo com que D2 diga outra coisa - "o texto é objeto" - que, de certa forma, nega ou contradiz o discurso que defende o gênero como objeto. Os movimentos de transitoriedade entre os objetos de ensino-aprendizagem marcados na escrita explicitam a dificuldade do sujeito, professor da educação básica, em articular seu dizer ao dizer teórico, em função, reiteramos, da força coercitiva do discurso outro e do discurso Outro.

Após a leitura do texto integral e a seleção dos segmentos presentes no Quadro 3, compreendemos que, assim como D1, D2 declara a opção por um objeto - gênero discursivo carta de leitor, mas também mobiliza, na escrita, o objeto texto. Os dois discursos são observados em D1 e D2, neste o objeto gênero do discurso marca-se com mais intensidade; naquele o objeto texto marca-se como maior intensidade.

\section{A leitura: relação entre o sujeito que diz e o que é dito por ele}


Ao iniciar este texto, anunciamos realizar um exercício de interpretação das atitudes de leitura dos sujeitos, professores que escreveram D1 e D2. Identificamos, nesse exercício, a presença de dois objetos de ensino-aprendizagem, o texto e o gênero discursivo, sendo este declarado e aquele apenas mobilizado, marcado linguisticamente, no texto. Entre esses dois objetos, há um movimento de transitoriedade, observado na escrita, por meio de dois processos discursivos: a sinonímia e a metonímia.

A presença desses dois processos indicia que D1 e D2 tiveram acesso a textos de fundamentos pertencentes às duas vertentes teóricas, a que defende o texto como objeto de ensino e a que defende o gênero. Não é possível afirmar que esse acesso ocorreu no processo de formação do ProfLetras, mas que essas leituras fazem parte da memória discursiva de D1 e de D2 e que esta é condição para a leitura e para escrita, direciona as atitudes de leitura e faz emergir o discurso, neste caso, comum entre os pares.

Convém reiterar que D1 e D2 são compreendidos como sujeitos. Ao compreendêlos assim, partimos da concepção presente em Pêcheux ([1988] 2009): o sujeito não é o centro do discurso; é cindido pelo inconsciente e interpelado pela ideologia. Nesse caso, o foco é o sujeito do dizer, não o indivíduo que diz. É possível projetar, assim, os professores que escreveram D1 e D2 como dois sujeitos inseridos em uma dada condição de produção, o espaço acadêmico de escrita de uma dissertação de mestrado, como requisito para uma titulação. Escrita marcada pelo viés da objetividade, que exige do sujeito uma tomada de posição, ao mesmo tempo que exige seu apagamento no texto.

Pêcheux (2014) explica o termo condição de produção com o argumento de que as circunstâncias determinam o dizer. O sentido é, assim, produzido a partir das circunstâncias. Não as imediatas que aproximariam o termo à noção de contexto ou situação, mas as circunstâncias históricas e sociais.

Considerando D1 e D2 sujeitos sócio-historicamente situados em uma dada condição de produção, que dialogam com outros sujeitos também situados e que estes intervêm na escrita daqueles, na estrutura do dizer, é necessário considerar que o sentido também é construído de forma relacional. Isso implica que, para compreender o dizer presente em $\mathrm{D}_{1}$ e em D2, é necessário estabelecer relação com outros dizeres.

Fairchild, em texto publicado em 2012, anuncia a coexistência dos dois objetos observados em nossa análise: o texto e o gênero discursivo como objeto de ensino- 
aprendizagem de língua portuguesa. Em sua abordagem, faz uma análise do processo de ascensão do objeto gênero e declínio do objeto texto. Tal análise é relevante para compreensão do que estamos defendendo, pois nos confirma que o acontecimento é, de fato, anterior à escrita de D1 e D2 e marca-se, na escrita, como efeito do interdiscurso. Segundo Fairchild:

\begin{abstract}
Duas frases correntes no ensino de língua hoje dizem que "o gênero é objeto de ensino" e "o texto é unidade de trabalho". [...] esses postulados recortam os contornos de uma proposta de escolarização que se tornou amplamente consensual no Brasil.

Elas pertencem a uma herança até certo ponto comum, já que derivam de leituras da obra de Bakhtin e se inserem no mesmo movimento de contraposição à gramática como fundamento do estudo da língua. Tem se tornado frequente, no entanto, o entendimento de que essas proposições se complementariam, traçando o contorno de uma proposta de ensino una e coesa, na qual a primeira afirmação prepondera sobre a segunda e o conceito de gênero envolve o de texto como uma cápsula. Esse entendimento se traduz na ideia de que o texto "materializa o gênero em sala de aula", e não materializa nada mais a não ser um gênero.

Essa leitura bastante particular dos dois enunciados acima tem tido como efeito empírico obscurecer o fato de que a assertiva 'o texto é unidade de trabalho' provém de uma posição teórica e política distinta daquela onde se produziu, posteriormente, a assertiva 'o gênero é objeto de ensino' (FAIRCHILD, 2012, p. 113 , grifo nosso) 3 .
\end{abstract}

O trecho que destacamos é atualizado por meio da análise da escrita de Di e de D2, conforme mostramos por meio dos processos discursivos por sinonímia e por metonímia. A coexistência desses objetos é uma realidade que se mostra no real da língua e no real da história, conduzindo a compreensão de que o sentido não é dado mais do que o sujeito. Ambos se produzem na história e esta se constitui um espaço de disputa. Embora haja uma tendência para que o gênero como objeto de ensino seja a concepção hegemônica, o outro discurso se mantém pela força do interdiscurso e faz com que D1 e D2 afirmem que o texto é unidade de ensino.

As relações apresentadas por Fairchild (2012) mostram que a construção do significado de texto e de gênero discursivo é fruto de um processo discursivo; os professores que escreveram D1 e D2 estão inseridos em um ambiente de formação, permeado por esses objetos, e por conceitos que os dão sustentação, através dos quais discussões são direcionadas, discursos são construídos, interdições são postas; são

${ }^{3}$ Ao citar "o texto é unidade de trabalho", Fairchild, em nota de rodapé referencia Geraldi (2004) e, ao citar "o gênero é objeto de ensino", aponta Schneuwly, Dolz, et al. (2004).

Revista Investigações, Recife, v. 32, n. 2, p. 522 - 547, Dezembro/2019 
espaços em que os dois enunciados citados por Fairchild (2012) e observados, na escrita de D1 e D2, circulam.

Assim, uma relação de lugares é estabelecida, nos quais os sujeitos são constituídos. A presença do primeiro enunciado - o gênero é objeto de ensino manifesta-se mais no plano intradiscursivo, enquanto efeito-sujeito. Já o texto como objeto de ensino, marca-se no interdiscursivo, na forma de discurso-transverso, uma vez que atravessa o texto, conforme mostraram as análises.

Nestas, observamos a escrita como espaço de memória, pois atualiza teorias e conceitos pelo peso da tradição acadêmica que elas possuem. Por meio do interdiscurso, o discurso explicita-se através de um "todo complexo com dominante" (PÊCHEUX, [1988] 2009, p. 149), ou seja, o que o discurso revela pelo interdiscurso é a força coercitiva de algo que foi dito antes, sobre o texto ou sobre o gênero discursivo. Não antes enquanto anterioridade, mas antes enquanto discurso que antecede o processo de leitura e de escrita dos textos em análise, o antes que direciona as atitudes de leitura de D1 e de D2.

O discurso de defesa do gênero como objeto de ensino também não é algo que se constituiu no decorrer das atividades de pesquisa, diagnóstico e escrita de D1 e de D2, mas algo que já estava posto e se materializou, no texto, por meio da escrita, conforme revela a leitura dos segmentos. Esse dado expressa a forma como a leitura pode ser condicionada por uma formação discursiva. Assim, no enunciado posto por D1 (L1-4), "somente um processo de ensino-aprendizagem pautado na articulação entre o trabalho com a leitura e a escrita de gêneros textuais, que circulam socialmente, pode contribuir, decisivamente, para atingir-se o propósito de formar leitores e produtores de textos proficientes", é possível observar, no funcionamento do discurso, um sujeito heterogêneo, constituído por filiações históricas e ideológicas, pois, ao mesmo tempo em que Dı defende a leitura e a escrita de gêneros textuais, argumenta ser preciso formar leitores e produtores de textos. Esse leitor e produtor de textos precisa ser proficiente, termo que reporta a outro discurso, que trouxe para o Brasil a pedagogia da competência.

O discurso em defesa dos gêneros textuais/discursivos como objeto de ensino de língua materna não se sustenta por uma necessidade presente no ensino-aprendizagem; não se revela como um caminho para a solução de um problema percebido por meio de um diagnóstico da realidade vivida por D1 ou por D2, antes de iniciar a atividade de Revista Investigações, Recife, v. 32, n. 2, p. 522 - 547, Dezembro/2019 
pesquisa isso já fora posto por outras instâncias discursivas. A associação do conceito de texto ao conceito de gênero discursivo não é fruto da leitura de D1 e de D2, como mostra Fairchild (2012), é fruto de processo de convencimento, no qual a voz teórica fundante é mantida, mas não preservada.

Nesse jogo, discursivamente mostrado, os conflitos explicitam-se: ora o ensino dos gêneros é um método de ensino; ora se expressa como concepção teórica; ora é conteúdo e objeto de ensino. O mesmo e o diferente que ajudam a criar a ideologia de um ensino exitoso e revelam como o professor tem se constituído um "professor genérico - caracterizado por um tipo de tratamento da linguagem mais distante de saberes disciplinares específicos (como a gramática ou a linguística) e mais próximo das operações linguageiras realizadas pelo falante comum" (FAIRCHILD, 2012, p. 114, grifo do autor).

Esse discurso em favor dos gêneros como objeto de ensino revela que os sentidos são construídos sócio-historicamente e transitam em espaços instituídos pelas formações discursivas. O discurso em defesa do gênero ou do texto como objeto de ensino-aprendizagem está, assim, presente na universidade, nas políticas públicas de formação de professores, nas políticas de ensino promovidas pelas instâncias governamentais, como é o caso da Olimpíada de Língua Portuguesa, e nas instâncias privadas representadas pelos sistemas de ensino que vendem a ideologia da excelência, como se o sucesso do processo de escolarização, do ensino de língua pudesse ser representado pelo uso de um objeto ou de um método de ensino, dispensando uma análise relacional (APLLE, 1982) do que está em sua volta.

Esse discurso em favor dos gêneros revela, ainda, que D1 e D2 são movidos pela busca de verdade, por aquilo que acreditam ser a verdade (FOUCAULT, 2014), revelam um querer acertar. As atitudes de leitura, as muitas vozes chamadas para o processo de escrita revelam uma tentativa de mobilizar a teoria, embora tenham resultado em conflito. Revelam ainda, segundo nos mostram Barbosa e Fabiano-Campos (2014), como é complexo dialogar com a palavra do outro, construir uma leitura própria e fazer da interpretação a base principal da produção escrita.

\section{Primeiras considerações finais}


Pelo fato de esta pesquisa ainda estar em desenvolvimento e de este artigo representar um exercício de escrita, no qual relacionamos o corpus às teorias que estamos mobilizando para compreendê-lo, o que temos são as primeiras considerações finais, desmembradas nos parágrafos que seguem.

Através das análises, verificamos a existência de discursos em conflito: ora o gênero discursivo é objeto de ensino; ora o texto é objeto de ensino; ora gênero discursivo equivale a texto, processo discursivo por sinonímia; ora o texto é parte do gênero, processo discursivo por metonímia; numa terceira vertente, gênero e texto são duas categorias diferentes. Esses processos discursivos marcaram-se na escrita, durante a tentativa de mobilização da(s) teoria(s) e dos objetos. Dado que mostra que os efeitos de sentido(s) marcam-se por meio dos movimentos feitos na escrita, mas se constroem numa relação que é anterior e exterior a ela.

A análise das condições de produção revela que os sentidos construídos, na escrita, marcam-se, por meio do interdiscurso, como tomada de posição do sujeito, enquanto efeito de identificação. D1 e D2 assinalam, na escrita, por meio do intradiscurso, a identificação com o discurso que defende o gênero como objeto de ensino, efeito-sujeito. Esse fio discursivo, todavia, se rompe pela força do interdiscurso que o atravessa verticalmente. D1 e D2 não conseguem sustentar esse efeito, pois uma memória discursiva os atravessa, na forma discurso-transverso. O objeto gênero é declarado, mas o objeto texto é marcado com mais recorrência na escrita.

D1 e D2 trazem, para a escrita, o peso da tradição e da atualidade no que se refere ao trabalho com os objetos gênero e texto no ensino de língua portuguesa. A busca por estabelecer relação entre os dois objetos desvela a dificuldade do sujeito em articular o dizer teórico ao seu dizer enquanto pesquisador, devido à força coerciva do discurso. A análise das condições de produção revela, portanto, que os sentidos construídos por meio da leitura, marcam-se como tomada de posição, efeitos de identificação.

\section{Referências}

APPLE, Michael W. Ideologia e Currículo. - São Paulo: Editora Brasiliense, 1982. 
BARBOSA, Marinalva Vieira; FABIANO-CAMPOS, Sulemi. A difícil arte de dialogar com a palavra do outro para produzir palavra própria. Revista Interdisciplinar. Ano IX, v.20, jan./jun. 2014, Itabaiana/SE, p. 35-46.

DUBOIS, Jean et. al. Dicionário de Linguística. São Paulo: Cultrix, 2006.

FAIRCHILD, THOMAS Massao. Velas que não iluminam: texto, gênero e a invenção do professor genérico. In: RIOLFI, Claudia. BARZOTTO, Valdir Heitor (Org.). Sem choro nem vela: carta aos professores que ainda vão nascer. São Paulo: Paulistana, 2012.

FOUCAULT, Michel. A ordem do discurso. 24. ed. São Paulo: Edições Loyola, 2014.

. A arqueologia do saber. 8. ed. Rio de Janeiro: Forense Universitária, 2015.

GADET, Françoise; PÊCHEUX, Michel. A língua inatingível. Campinas, SP: Pontes, 2004. GINSBURG, Carlo. Mitos, emblemas, sinais: morfologia e história. 2. ed. São Paulo: Companhia das Letras, 1989.

HENRY, Paul. A ferramenta imperfeita: língua, sujeito e discurso. 2. ed. Campinas, SP: Editora da Unicamp, 2013.

PÊCHEUX, Michel. Semântica e discurso. 4. ed. Campinas, SP: Editora da Unicamp, 2009 .

Ler o arquivo hoje. In: ORLANDI, Eni P. (org.). Gestos de leitura: da história no discurso. 3. ed. - Campinas, SP: Editora da Unicamp, 2010.

Análise automática do discurso (AAD-69). In: GADET, F.; HAK, T. Por uma análise automática do discurso: uma introdução à obra de Michel Pêcheux. 3. ed. Campinas, SP: Editora da Unicamp, 2014.

. O discurso: estrutura ou acontecimento. 7. ed. Campinas, SP: Pontes, 2015 .

Análise do discurso. 4. ed. Campinas, SP: Pontes Editores, $2015 \mathrm{a}$.

. Papel da memória. In: ACHARD, Pierre et. al. Papel da Memória. 4. ed.

Campinas, SP: Pontes Editores, 2015b.

\footnotetext{
${ }^{*}$ Professora Associada I do Departamento de Letras, do Programa de Pós-graduação em Estudos da Linguagem e do Mestrado Profissional da Universidade Federal do Rio Grande do Norte.

** Professora Assistente da Universidade Federal do Maranhão. Doutoranda em Estudos da Linguagem na Universidade Federal do Rio Grande do Norte, com estudos na linha de Linguística Teórica e Descritiva, com foco nos estudos do texto e do discurso.
} 